\title{
TRADUÇÃO FEMINISTA: CONTEXTOS, PRÁTICAS E TEORIAS ${ }^{1}$
}

\author{
Luise von Flotow 1 \\ -University of Ottawa, Ottawa, Canada \\ Tradução de Ofir Bergemann De Aguiar²² \\ Lilian Virginia Porto 2 \\ ${ }^{2}$ Universidade Federal de Goiás, Goiânia, Goiás, Brasil
}

Ou, Como traduzir “Ce soir j'entre dans l'histoire sans relever ma jupe". ${ }^{2}$

Gostaria de abrir este ensaio com um problema de tradução específico de La Nef des sorcières ${ }^{3}$, uma obra dramática produzida por um grupo de mulheres feministas, no Quebec, em 1976. O problema é como traduzir a seguinte fala: “Ce soir j'entre dans l'histoire

\footnotetext{
${ }^{1}$ N. das T.: Originalmente publicado no periódico TTR: Traduction, Terminologie, Rédaction (4.2, (1991): 69-84). Agradecemos à autora do artigo, Dra. Luise von Flotow, e à editora da revista TTR, Dra. Aline Francoeur, pela permissão concedida para a realização e publicação desta tradução.

${ }^{2}$ Foram apresentadas várias versões orais deste ensaio: na conferência do CIEF (Conselho Internacional de Estudos Francófonos) na Martinica, 1990, e no encontro da CATS (Associação Canadense de Estudos de Tradução) em Kingston, Ontário, em 1991.

${ }^{3}$ Brossard, N., France Théoret, et al., La Nef des sorcières (Montreal: Quinze, 1976) foi escrita por diversas autoras e atrizes. Estreou em 5 de março de 1976, no Teatro do Nouveau-Monde, em Montreal. Os dois tradutores a quem se faz referência aqui são, respectivamente, David Ellis e Linda Gaboriau. A tradução de Gaboriau do texto de Brossard, "L'Écrivain", foi publicada como “The Writer", na Fireweed, (1979-80): 5-6.
} 
sans relever ma jupe”. Existem dois tradutores disponíveis para o trabalho: um com visões mais ou menos tradicionais quanto à importância da "fidelidade" e equivalência em tradução, que acredita que o trabalho de um tradutor deve ser transparente e silencioso. $\mathrm{O}$ outro é uma tradutora feminista. O tradutor mais tradicional verte essa fala da peça da seguinte maneira: "this evening I'm entering history without pulling up my skirt" ${ }^{4}$. Parece uma versão perfeitamente adequada, idiomática, do texto na língua-fonte, embora eu prefira a mais coloquial "without hiking up my skirt" 5 . A tradutora feminista, por sua vez, traduz da seguinte maneira: "this evening I'm entering history without opening my legs" ${ }^{6}$. Essa é uma supertradução chocante, inaceitável, uma deliberada superinterpretação do texto original? A tradutora está tomando liberdades ultrajantes com uma fala que é relativamente anódina no francês? Está sendo deliberadamente sensacionalista?

Devo aqui acrescentar que esse exemplo foi usado várias vezes antes, porém ainda é apropriado como uma ilustração de uma prática corrente na tradução canadense. Tirei-o diretamente de um artigo de Barbara Godard, uma das primeiras tradutoras feministas do Canadá, e ela o tirou de um artigo anterior de Évelyne Voldeng $^{7}$; um círculo restrito, que pode também mostrar como poucos tradutores e críticos literários no Canadá são sensíveis às questões feministas. É ainda mais digno de nota, então, que um pequeno número de tradutoras canadenses tenha a audácia de proclamar uma abordagem antitradicional, agressiva e criativa da tradução que chamam de tradução feminista.

Meu estudo dessa prática de tradução não se refere a qual dessas duas traduções apresentadas anteriormente é a melhor, ou mais apropriada, ou mais fiel. Em vez disso, estou interessada no contexto, nas práticas e nas teorias subjacentes que tornam aceitável,

\footnotetext{
${ }^{4} \mathrm{~N}$. das T.: "esta noite entro para a história sem erguer a saia".

${ }^{5} \mathrm{~N}$. das T.: "sem levantar a saia”.

${ }^{6} \mathrm{~N}$. das T.: "esta noite entro para a história sem abrir as pernas".

7 B. Godard, "Translating and Sexual Difference" em Resources for Feminist Research 13.3, (1984): 13-16.
} 
até desejável, a tradução feminista "without opening my legs". Ao comentar essa evidente supertradução, Godard, por exemplo, elogiou seu "efeito de choque" e o fato de deixar explícito o que está implícito no texto feminista - "a retomada da palavra pelas mulheres e a nomeação da vida do corpo tal como experimentada pelas mulheres"8 (Godard, "Preface to These Our Mothers", 14). Considero a importância crescente desse tipo de tradução, assim como sua visibilidade progressiva, intrigantes e potencialmente revigorantes como uma nova abordagem para o trabalho de tradução.

Baseio minha reivindicação pela importância do fenômeno da tradução feminista no Canadá em dois fatores: os números crescentes de traduções para o inglês descritas, de forma autoconsciente, como feministas e o número crescente de textos feministas sendo hoje traduzidos no Canadá. Nos últimos anos, quase toda a obra feminista radical de Nicole Brossard foi traduzida por Barbara Godard, Marlene Wildeman e Fiona Strachan, e seu romance Désert mauve acaba de ser publicado na tradução de Susanne de Lotbinière-Harwood $^{9}$. De modo similar, a obra inicial de France Théoret será lançada em breve em uma coletânea, The Tangible Word, traduzida por Godard, e eu acabei de traduzir L'Homme qui peignait Staline ${ }^{10}$. Um primeiro volume da obra de Madeleine Gagnon apareceu na tradução de Howard Scott, o único homem que se descreve como um tradutor feminista, e L'Euguélionne, de

\footnotetext{
${ }^{8}$ N. das T. : em inglês no artigo de Flotow. Todas as citações em inglês do corpo do texto foram vertidas para o português pelas tradutoras.

${ }^{9}$ Os seguintes livros feministas radicais de Nicole Brossard apareceram em tradução canadense: These Our Mothers (Toronto: Coach House, 1983), Lovhers (Montreal: Guernica, 1987) e Picture theory (Montreal: Guernica, 1991), traduzidos por Barbara Godard; Surfaces of Sense (Toronto: Coach House, 1989), traduzido por Fiona Strachan; The Aerial Letters (Toronto: Women's Press, 1988), traduzido por Marlene Wildeman, e Mauve Desert, por Susanne de Lotbinière-Harwood.

${ }^{10}$ A obra inicial de Théoret será publicada em uma tradução de Barbara Godard The Tangible Word (Montreal: Guernica Press, 1991). Minha tradução de L'Homme qui peignait Staline foi publicada pela Mercury Press, Stratford, Ont. em 1991.
} 
Louky Bersianik, está sendo retraduzido por Scott ${ }^{11}$. Por fim, Lettres d'une autre, de Lise Gauvin, foi deliberadamente transformado em um texto feminista em sua versão traduzida para o inglês, e premiada, de Lotbinière-Harwood ${ }^{12}$. Quase invariavelmente essas publicações são prefaciadas por comentários que descrevem o trabalho como tradução feminista.

\section{Contextos}

Fica evidente, do anteriormente exposto, que a atual escrita do Quebec está na raiz desse fenômeno e eu gostaria de resumir rapidamente os contextos cultural e social subjacentes a ele. A tradução feminista parece ter se desenvolvido como um método de tradução do enfoque e da crítica à "linguagem patriarcal" pelas escritoras feministas no Quebec. No final dos anos 70 e no início dos anos 80, as escritoras quebequenses que mencionei anteriormente, entre outras, produziam trabalho altamente experimental e constituíram esforços para atacar, desconstruir, ou simplesmente evitar a linguagem convencional que percebiam como inerentemente misógina. Nas palavras de um crítico do período: "Les femmes injectent un sang neuf $[\ldots]$ et le déplacement du propos s'effectue autant dans le trajet que dans le projet de leurs créations"13 (Sabourin 129). Se definirmos apressadamente seu "projet" como a elaboração de uma "écriture au féminin" ${ }^{14}$, uma

${ }^{11}$ Howard Scott publicou Lair (Toronto: Coach House, 1989), uma tradução de Antre, de Madeleine Gagnon, e está preparando uma nova tradução de L'Euguelionne, de Louky Bersianik.

${ }^{12}$ Susanne de Lotbinière-Harwood publicou traduções de textos curtos de Nicole Brossard, assim como Letters from Another (Toronto: Women's Press, 1989), de Lise Gauvin. Ela também está trabalhando na tradução de Heroine, de Gail Scott, para o francês, um processo que a levou a fundamentar uma recente palestra na necessidade de as mulheres se reapropriarem da palavra "con"* em francês. [*N. das T.: "cona"]. ${ }^{13} \mathrm{~N}$. das T.: "As mulheres injetam um sangue novo [...] e o deslocamento do propósito ocorre tanto no trajeto quanto no projeto de suas criações".

${ }^{14} \mathrm{~N}$. das T.: "escritura no feminino"

Cad. Trad., Florianópolis, v. 41, no 2 p. 492-511, mai-ago, 2021. 
cultura literária feminista, então seu "trajet" foi um ataque à linguagem convencional - "le déplacement du propos".

Os textos dessas escritoras eram, portanto, frequentemente voltados para uma investigação formalista da materialidade da linguagem, uma tendência remanescente da anterior modernité do Quebec. Elas estavam envolvidas com pesquisa sobre a etimologia do vocabulário convencional e sua desconstrução. Exploraram experiências de mulheres que não tinham sido colocadas em palavras antes e tentaram escrever "l'inédit"15. Buscaram criar um novo idioma com o qual pudessem expressar essas experiências do corpo e escrever uma utopia das mulheres. $\mathrm{O}$ "e" silencioso, que marca o gênero feminino no francês, tornou-se um elemento importante na crítica do masculino como um termo genérico; foi explorado como um elemento mutante com o qual neologismos e trocadilhos puderam ser desenvolvidos para parodiar e atacar a linguagem convencional. Outras estratégias incluíram a fragmentação da linguagem, a desconsideração com as estruturas gramaticais ou sintáticas e o desmantelamento de palavras individuais a fim de examinar seus significados ocultos: o uso que Brossard faz da palavra "dé-lire" para significar tanto a expressão delirante e descontrolada das realidades e fantasias das mulheres, quanto o processo de desler - DÉ-LIRE -, ou ler contra a corrente, é um bom exemplo desse trabalho com a linguagem.

Bersianik utilizou uma outra abordagem. Sua crítica etimológica da linguagem convencional permeia L'Euguélionne e ela permanentemente manipula a linguagem para parodiar o "conhecimento" patriarcal. Por exemplo, sua crítica à definição do dicionário para a palavra "viril", que descreve características como energia, atividade e coragem como típicas de homens, tanto revela a arrogância do conhecimento convencional, como mostra com que facilidade ela também pode manipular a linguagem:

15 "Inédit"* é um termo privilegiado na escrita de Brossard, que se refere ao que não pode ser inscrito por falta de linguagem apropriada. [*N. das T.: “o inédito"].

Cad. Trad., Florianópolis, v. 41, no 2 p. 492-511, mai-ago, 2021. 
un peu de modestie, messieurs les Virils. N'oubliez pas que le mot 'verge' qui veut dire 'baguette' a donné le diminutif 'virgule'... ${ }^{16}$ (Bersianik 356)

São essas somente duas das muito diferentes abordagens adotadas por escritoras feministas do Quebec nos anos 70 e início dos anos 80 para demolir o poder do discurso convencional. Apesar de suas diferentes estratégias, políticas e personalidades, elas compartilhavam o sentimento geral de que a "linguagem patriarcal" convencional e prescritiva tinha de ser desfeita, para que as palavras das mulheres se desenvolvessem, encontrassem um espaço e fossem ouvidas.

A tradução desses textos do Quebec começou no final da década de 1970 com duas peças feministas La Nef des sorcières e Les Fées ont soif ${ }^{17}$. A antologia The Story so far $^{18}$, editada por Brossard, foi um outro marco histórico e, gradualmente, o corpus das obras feministas traduzidas do Quebec passou a incluir textos de conferências, trabalhos apresentados nos encontros de escritoras trans-canadenses e, por fim, livros completos. A tradução feminista é, portanto, um subproduto direto do trabalho experimental das escritoras do Quebec; é um fenômeno intimamente ligado a uma prática de escrita específica em um ambiente ideológico e cultural específico, o resultado de uma conjuntura social específica. Tratase de uma abordagem da tradução que aproveitou e adaptou muitas das técnicas e teorias subjacentes à escrita que traduz.

\section{Práticas}

Existem várias estratégias utilizadas na tradução feminista, das

\footnotetext{
${ }^{16}$ N. das T.: "um pouco de modéstia, Senhores Viris. Não se esqueçam de que a palavra 'virga', que quer dizer 'vara' deu origem ao diminutivo 'vírgula'..."

${ }^{17}$ Denise Boucher, Les Fées ont soif (Montreal : Éditions Intermède, 1978) foi traduzida como The Fairies are thirsty (Vancouver : Talonbooks, 1982).

${ }^{18}$ Nicole Brossard. (Ed). Les Stratégies du réel, traduzida como The Story so far, (Toronto: Coach House, 1979), por vários tradutores diferentes.
} 
quais discutirei, aqui, somente três - suplemento, prefácios e notas de rodapé e "sequestro". Basta dizer, como uma breve introdução, que a tradutora feminista, seguindo o exemplo das escritoras feministas que traduz, deu-se permissão para tornar seu trabalho visível, discutir o processo criativo no qual está engajada, conspirar com as escritoras que traduz e desafiá-las.

\section{Suplemento}

Uma vez que a "linguagem patriarcal" e suas instituições governam a maioria dos aspectos da linguagem convencional, seja em inglês, francês ou qualquer outra língua, as tradutoras que vertem textos feministas quebequenses para o inglês tiveram de transformar a crítica de uma língua na crítica de outra. O ensaio de Howard Scott sobre como traduzir Bersianik deixa isso claro. Ele não quis "transmitir, ao leitor do inglês, o que Bersianik diz sobre o francês, afirma, mas sim adaptar a mensagem dela para o inglês e mostrar como a língua inglesa é sexista" - pareil, mais autrement ${ }^{19}$. Concretamente, isso significa séria interferência no texto. Suplemento, como sabemos pelo texto de Benjamin "Die Aufgabe des Ubersetzers", é um dos aspectos mais positivos da tradução. É o aspecto que sempre tenho em mente quando enfrento textos aparentemente intraduzíveis. De acordo com Benjamin, o texto-fonte é suplementado por sua tradução, amadurecido, desenvolvido e ganha uma sobrevida. É precisamente o que acontece com a suplementação na tradução feminista, com a diferença de que a tradutora feminista é consciente de seu papel político como mediadora, ao passo que Benjamin parece conceber a tradução, ou qualquer obra de arte, a esse respeito, como apolítica e não destinada primeiramente para um público.

Suplemento, na tradução feminista, é uma estratégia que pode explicar a "supertradução" do exemplo anterior "without

${ }^{19}$ N. das T.: o mesmo, mas de outro modo. 
opening my legs". Compensa as diferenças entre as línguas ou constitui "ação voluntarista" sobre o texto. Pois, mesmo que o inglês não tenha exatamente os mesmos problemas de gênero ou etimologia, há outros lugares no texto em que um déplacement ${ }^{20}$ similar da linguagem pode ser realizado. Temos um bom exemplo disso na tradução de L'Euguélionne, de Bersianik, feita por Scott. Em um texto em que a política de aborto estava sob escrutínio, a seguinte fala surgiu:

"Le ou la coupable doit être punie" $"$.

O "e" extra no particípio passado "puni" indica, claramente, que a mulher é que é punida pelo aborto. Mas essa sutileza não é diretamente transferível para o inglês que não possui concordância de gênero. A solução "voluntarista" de Scott suplementa essa falta particular no inglês e tem a seguinte redação:

"The guilty one must be punished, whether she is a man or a woman". ${ }^{22}$

Esse tradutor feminista, assim, recupera algumas perdas, intervindo e suplementando em outra parte do texto. Suplementa, também, o texto original, tornando sua crítica da linguagem aplicável ao inglês e significativa para os leitores de língua inglesa.

Godard utilizou outra estratégia na sua tradução do título da obra L'Amèr, de Nicole Brossard. A palavra é um neologismo, em francês, que contém pelo menos três termos: mère (mãe), mer (mar) e amer (amargo). Os temas da mãe patriarcal - a mulher reduzida à reprodução, seu sufocamento nesse trabalho não reco-

\footnotetext{
${ }^{20} \mathrm{~N}$. das T.: deslocamento

${ }^{21} \mathrm{~N}$. das T.: "O ou a culpada deve ser punida”.

${ }^{22} \mathrm{~N}$. das T.: "O culpado deve ser punido, seja ela um homem ou uma mulher".
} 
nhecido e sua tendência subsequente a sufocar seus próprios filhos - permeiam a primeira parte do livro. Godard, suplementando o jogo de palavras intraduzível do título, cujo efeito repousa no "e muet" ${ }^{23}$ e nas associações de som no francês, inclui um tipo de "explication de texte" ${ }^{24}$ na sua versão. Seu título torna-se "The Sea Our Mother" + "Sea (S)mothers + "(S)our Mothers" para, finalmente, terminar com:

\section{The $\mathrm{e}$ \\ $\checkmark$ our \\ mothers.}

Ele inclui os aspectos amargo ${ }^{25}$ e sufocante ${ }^{26}$ da maternidade patriarcal, além da associação do $m e r^{27}$ e mère ${ }^{28}$, suplementando a falta do " $\mathrm{e}$ " silencioso, no inglês.

\section{Prefácios e notas de rodapé}

Mais recentemente, intervenções feministas tomaram outras formas. Tem-se tornado quase rotina, para as tradutoras feministas, refletirem sobre seu trabalho, em um prefácio, e ressaltarem sua presença ativa no texto, em notas de rodapé. A tradutora modesta, discreta, que produz uma versão fluente, legível, do original, na língua-alvo, tornou-se coisa do passado. Conforme afirmou Godard, a tradutora feminista busca exibir sua assinatura em itálico, nas notas de rodapé e nos prefácios, deliberadamente womanhan-

\footnotetext{
${ }^{23}$ N. das T.: "e mudo"

${ }^{24} \mathrm{~N}$. das T.: "explicação do texto"

${ }^{25} \mathrm{~N}$. das T.: sour

${ }^{26} \mathrm{~N}$. das T.: smothering

${ }^{27} \mathrm{~N}$. das T.: sea

${ }^{28} \mathrm{~N}$. das T.: mother
} 
dling ${ }^{29} \mathrm{o}$ texto e ativamente participando da criação do significado (Godard, "Theorizing Feminist Discourse/Translation" 50).

Ela é mais do que uma tradutora convencional; é a cúmplice da autora, mantém a estranheza do texto-fonte e busca, ao mesmo tempo, comunicar seus múltiplos significados que, de outra forma, estariam "perdidos na tradução". Há um forte veio didático nessa estratégia. Por exemplo, no seu prefácio a These Our Mothers, de Nicole Brossard, Godard explica os jogos de palavras que não podiam ser traduzidos - o jogo com o "e" silencioso do francês - e interpreta a intenção deles : o "e", afirma ela, é descartado pela autora em palavras como "laboratoir" para marcar a ausência do feminino nas atividades realizadas ali ${ }^{30}$. Foi removido do título L'Amèr, continua, para "sublinhar o processo de articulação do silêncio das mulheres e de direcionamento a uma gramática neutra" (Godard, "Preface to These Our Mothers"7). Ela indica, então, suas atividades de suplementação - formas gráficas, trocadilhos mais familiares às feministas anglófonas e, em uma manobra pedagógica final, chama atenção para outros aspectos do texto que o secular (isto é, leitor, não acadêmico, do inglês) pode não notar: nesse caso, o discurso filosófico francês contemporâneo inscrito no texto.

A tradução está marcada por suas interferências: por exemplo, a fala "J'ai tué le ventre et fait éclater la mer" ${ }^{31}$ (20) tornou-se, em inglês, "I have killed the womb and exploded the Sea/Sour mother" (14), uma referência à sua intervenção no título. Há notas de rodapé com referências a intertextos literários: a $L$ 'Étranger (25), de Camus, e a Confessions d'un promeneur solitaire (83), de Rousseau. E onde quer que Brossard use a palavra "histoire" ${ }^{32}$, em in-

\footnotetext{
${ }^{29} \mathrm{~N}$. das T.: manipulando como mulher

${ }^{30} \mathrm{~N}$. das T.: no laboratório.

${ }^{31} \mathrm{~N}$. das T.: Matei o ventre e explodi o mar

${ }^{32} \mathrm{~N}$. das T.: história
}

Cad. Trad., Florianópolis, v. 41, no 2 p. 492-511, mai-ago, 2021. 
glês aparece His-story ${ }^{33}$. Em Lovhers ${ }^{34}$, uma brilhante tradução do título da obra Amantes, de Brossard, um prefácio à tradução ainda mais longo, de Godard, tanto contextualiza e interpreta o texto de Brossard, como discute a tradução.

A versão em inglês, de Marlene Wildeman, de La Lettre aérienne, de Brossard, também é prefaciada e marcada pelas intervenções da tradutora. Notas de rodapé, por todo o texto, especificam intertextos que a própria Brossard não indicou: por exemplo, "le corps certain" ${ }^{35}$ (20) é atribuído a The Pleasure of the Text (44), de Barthes, e Wildeman chega a dar os números das páginas do texto de Barthes, na tradução para o inglês, em que esse conceito é desenvolvido. Referências a páginas de textos de Djuna Barnes, Gertrude Stein, Luce Irigaray, Mallarmé e outros são fornecidas por toda a parte, embora nem os autores nem suas obras, muito menos as referências de páginas, sejam citados diretamente no texto-fonte. Além disso, as múltiplas conotações de Brossard são explicadas em copiosas notas da tradutora: por exemplo, a frase da autora "C'est le désir de la réplique" ${ }^{36}$ (136) é desenvolvida em uma longa nota de rodapé na versão em inglês (143). De modo semelhante, as dificuldades com neologismos como o termo essentielle $^{37}$ são discutidas no prefácio e, então, ressaltadas em notas de rodapé. $\mathrm{Na}$ abordagem de Wildeman, uma tradução feminista torna-se um instrumento educacional apoiado por pesquisa acadêmica. Aqui, a questão do público alvo é muito importante.

No prefácio, a tradutora se pergunta se está traduzindo para feministas canadenses apenas e "assim transportando uma carta de estatura internacional para aeroportos regionais somente?" (Wildeman 27) ou se deve visar a feministas norte-americanas,

\footnotetext{
${ }^{33} \mathrm{~N}$. das T.: história dele.

${ }^{34} \mathrm{~N}$. das T.: O acréscimo do " $\mathrm{h}$ " em "lovers" (amantes) propicia o possessivo feminino "hers" (delas) e remete ao substantivo feminino "amantes" (as amantes) do francês.

${ }^{35}$ N. das T.: "o corpo certo"

${ }^{36}$ N. das T.: "É o desejo da réplica”

${ }^{37} \mathrm{~N}$. das T.: essencial no feminino
} 
em outras palavras, americanas, com o risco de encobrir as diferenças Can/Am. Ela parece ter optado pelo mercado mais amplo e preparado um texto para uso em programas de Estudos da Mulher em qualquer lugar da América. Com a abrangente introdução de Louise Forsyth, as bases da literatura quebequense/ canadense são $\operatorname{cobertas}^{38}$.

Talvez essa crescente aspiração ao reconhecimento internacional, e o apelo ao mercado dos EUA, seja parcialmente responsável pela terceira estratégia da tradução feminista que quero aqui discutir.

\title{
Sequestro
}

Tomei o termo "sequestro" de um crítico da tradução feminista, um jornalista de Montreal (um tradutor), que ataca Susanne de Lotbinière-Harwood por sua excessiva interferência na tradução de Lettres d'une autre, de Lise Gauvin:

\begin{abstract}
A tradutora [...] é tão intrusiva, às vezes, que quase sequestra a obra da autora. Na introdução, ela nos conta que pretende fazer que sua presença seja sentida [...] para tanto, frequentemente invade a obra de Gauvin, explicando o que Gauvin realmente quis dizer e, por vezes, oferecendo, na página, o equivalente em francês para o inglês. $\left(\right.$ Homel) ${ }^{39}$
\end{abstract}

\footnotetext{
${ }^{38} \mathrm{O}$ apelo ao mercado acadêmico americano, penso, é cada vez mais importante. Em um clima de "decanonização" nos Estados Unidos e uma moda crescente das literaturas marginais, sejam canadenses, francófonas ou lésbicas radicais, faz sentido ter em vista os grandes estabelecimentos acadêmicos e orçamentos. Em um clima acadêmico em que programas de Estudos da Mulher e cursos sobre a escrita de mulheres são a regra, e não uma exceção, faz sentido praticar e proclamar intervenções feministas deliberadas nos textos.

${ }^{39}$ Agradeço Annie Brisset por reunir e me enviar tanto o artigo de Homel como a resposta de Lotbinière-Harwood.
} 
Ele ainda critica o trabalho pelas excessivas notas de rodapé e estreita abordagem didática. Na sua visão, o livro de Gauvin tornou-se um "manual informal sobre a cultura contemporânea do Quebec" e foi ideologicamente "corrigido" (isto é, feminizado), para além da intenção original da autora. A tradutora respondeu que (a) a tradução, de fato, visou a um público norte-americano, incluindo faculdades e universidades, e que notas explicando o referendo e tourtière ${ }^{40}$ eram, portanto, justificáveis, e que (b) ela trabalhou em estreita colaboração com a autora na versão em inglês, do que eu deduzo que ela teve a permissão dela para "corrigir" o texto.

Especialmente interessante nesse trabalho de "correção" é a feminização deliberada do texto-alvo pela tradutora, o que ela anuncia, no seu prefácio, como uma intervenção política:

Lise Gauvin é uma feminista, e eu também. Mas não sou ela. Ela escreveu no masculino genérico. Minha prática de tradução é uma atividade política destinada a fazer que a linguagem fale pelas mulheres. Então, minha assinatura em uma tradução significa: esta tradução utilizou todas as estratégias de tradução possíveis para tornar o feminino visível na linguagem. Porque tornar o feminino visível na linguagem significa fazer as mulheres serem vistas e ouvidas no mundo real. É disso que trata o feminismo. (De Lotbinière-Harwood 9)

Ao fazer o feminino ser visto e ouvido em sua tradução, de Lotbinière-Harwood deliberadamente contraria a prática de tradução convencional de ser transparente e silenciosa. Suas estratégias incluem usar a palavra Québécois-e-s onde quer que o genérico Québécois ${ }^{41}$ ocorra no original - uma tática de feminização da língua-fonte que é explicada no seu prefácio. Ela evita outros

\footnotetext{
${ }^{40}$ N. das T.: torta tradicional do Quebec.

${ }^{41} \mathrm{~N}$. das T.: quebequense.
} 
termos genéricos masculinos em inglês, embora eles apareçam em francês, isto é, "la victoire de l'homme" ${ }^{42}$ torna-se "our victory [...] over the elements" ${ }^{43}$; coloca o elemento feminino em primeiro lugar em expressões como "mulheres e homens", "delas ou deles", e utiliza aspas invertidas para enfatizar alguns dos absurdos do inglês convencional, por exemplo, a referência às mulheres como "masters" ${ }^{44}$ da cozinha.

De Lotbinière-Harwood, de fato, "sequestrou" o texto, apropriou-se dele, fez dele o seu próprio texto, para expressar suas intenções políticas. E o fato de que essa tradução tenha ganhado o prêmio concedido para a tradução da literatura franco-canadense pela Columbia University, em 1991, valida ainda mais suas estratégias. Nesse caso, o conluio da tradutora com a autora, penso eu, é de importância secundária. Aqui, a tradutora está escrevendo por si mesma.

\section{Teorias e efeitos}

É difícil e, provavelmente, desnecessário apontar teorias específicas que tenham validado a abordagem feminista da tradução. Em geral, pode-se dizer que a erosão da autoridade do Autor/Original nos discursos pós-estruturalistas e desconstrutivistas dos últimos vinte anos foi, certamente, de grande importância, dando à tradutora uma maior liberdade com o texto.

A revisão derridiana de conceitos-chave da filosofia ocidental, cujas nuanças eram realmente "perdidas na tradução", estimulou um renovado interesse no trabalho da tradutora ${ }^{45}$ e deu-lhe o direi-

\footnotetext{
${ }^{42}$ N. das T.: "a vitória do homem"

${ }^{43}$ N. das T.: "nossa vitória [...] sobre os elementos"

${ }^{44}$ N. das T.: "mestres"

${ }^{45}$ Ver Des Tours de Babel, de Derrida, em Difference in Translation, Joseph P. Graham (Ed.), (Cornell University Press, 1985). Também a retradução de Derrida do termo economy, em sua longa nota de rodapé para "Survive", em Parages (Paris: Galilée, 1986), e sua crítica do termo pharmakon, baseada na sua tradução parcial, em La Dissémination (Paris: Éditions du Seuil, 1972).
} 
to, mesmo o dever, de "abusar" do texto-fonte ${ }^{46}$. De fato, todo o projeto pós-estruturalista de questionamento das narrativas mestras, de desafio das verdades definitivas e de exploração da relatividade no significado forçou a tradução a tornar-se uma atividade criativa. E tradutores dos textos de Derrida, lidando com as ambivalências, ambiguidades e múltiplos significados de sua escrita, salientaram, de modo consistente, em seus prefácios, a necessidade de criatividade e experimentação, definindo, assim, um novo tom na prática da tradução. No prefácio à sua tradução de Dissemination, de Derrida, Barbara Johnson, para dar um exemplo, reivindica "tradução forte, vigorosa, que valoriza experimentação, confronta o uso, busca corresponder às polivalências e plurivocidades ou tensões expressivas do original produzindo as suas próprias" - exatamente o que as tradutoras feministas no Canadá estão fazendo.

Por fim, a influência da segunda onda do feminismo foi vital para a tradução feminista. Dotou tanto as escritoras feministas do Quebec quanto suas tradutoras com a autoridade e com os meios para desconsiderar a Autoridade. Com a autoria e a "linguagem patriarcal" desmistificadas, a tradutora feminista pode ousar ser uma escritora resistente, agressiva e criativa que não somente confronta os aspectos ELE/Homem da linguagem convencional, mas intervém no texto de muitas outras maneiras. Além disso, com a atual exploração teórica do léxico da sexualidade e especialmente da diferença sexual - jouissance, dissémination, invagination, hymen ${ }^{47}$ etc - as sutis conexões entre gênero, definições de mímesis ou fidelidade na escrita e tradução tornaram-se óbvias, e as tradutoras feministas estão atacando em pelo menos duas direções de uma só vez: no uso per se da linguagem convencional e nas visões tradicionais da tradução.

É aqui que entra o aspecto dos efeitos de longo prazo da tradução feminista que, a meu ver, tem certo potencial de desenvolvimento,

${ }^{46}$ Philip Lewis argumenta que somente a tradução "abusiva” pode fazer justiça a textos contemporâneos que buscam uma crítica à linguagem "falologocêntrica" convencional. Ver seu artigo “The Measure of Translation Effects”, em Difference in Translation, op.cit. nota 45.

${ }^{47}$ N. das T.: gozo, disseminação, invaginação, hímen 
se não de revolução. Recente trabalho de Lori Chamberlain ${ }^{48}$ sobre metáforas de tradução mostrou que as concepções mais tradicionais e misóginas de papéis e atributos de gênero pautaram grande parte da discussão sobre tradução, codificando-a como uma atividade passiva e subserviente que simplesmente reproduz a verdadeira obra de outra pessoa. E, como todos sabemos, o trabalho de reprodução, de seres humanos ou textos, embora absolutamente vital para os empreendimentos literários ou humanos, é, geralmente, mal remunerado, subvalorizado, até mesmo desprezado nas estruturas hierárquicas que definem nossa cultura. A reprodução tem sido, historicamente, o trabalho das mulheres; e os tropos utilizados para descrever a tradução, embora ressaltem a necessidade de manutenção do controle da reprodução de textos (filhos), refletem sua subalternidade. De fato, o discurso sobre a tradução serviu, permanentemente, para expressar a diferença, em valor, entre o original e sua "reprodução", e, rotineiramente, utilizou metáforas de estupro e violência contra as mulheres e de controle paternalista para manter essa diferença. Com isso, os tropos tradicionais utilizados para a tradução refletiram as relações de poder entre os sexos e revelaram o medo do materno (ou da língua mãe), a necessidade de sua proteção (controle), assim como a necessidade de conservar a posse dos filhos (textos).

Trata-se de um discurso que, com expressões como "les belles infidèles" ${ }^{49}$, manteve o uso de dois pesos e duas medidas com base em estereótipos de gênero tradicionais, de acordo com os quais textos belos e mulheres belas só podem ser infiéis e textos fiéis são feios, por definição, assim como mulheres feias (uma contradição nos termos) não podem deixar de ser fiéis. Essa metafórica persistiu em bem recente trabalho de escritores como Serge Gavronsky, que celebra sua libertação da fidelidade excessiva ao original como um processo de "captura e prática de estupro e incesto" no texto ${ }^{50}$.

${ }^{48}$ Lori Chamberlain, "Gender and the Metaphorics of Translation", em Signs: Journal of Women in Culture and Society 13.3, (1988): 454-472.

49 "as belas infiéis"

${ }^{50}$ Citado por Chamberlain, p. 462, "The Translator: From Piety to Cannibalism", de Serge Gavronsky, em Sub-stance, 16 (1977). 
Parece evidente que, ao conceber e praticar abordagens da tradução criativas não tradicionais, ao fazer sua presença ser sentida nos textos e ao desafiar suas autoras, as tradutoras feministas no Canadá estejam fazendo mudanças em algumas dessas visões tradicionais e na posição "missionária" habitual atribuídas à tradução. A prática da tradução e, em um sentido teleológico, o desenvolvimento da linguagem só têm a ganhar com essas novas abordagens ${ }^{51}$. Com noções de fidelidade e verdade, transparência e significado definitivo na tradução dando lugar a suplementação, experimentação, interferência e "transformance" ${ }^{52}$, e com a conscientização feminista inscrita em muitos aspectos de nossa escrita contemporânea, há, então, todas as razões para que "This evening I'm entering history without opening my legs" seja uma versão contemporânea válida de "Ce soir j'entre dans l'histoire sans relever ma jupe".

${ }^{51}$ Em resposta a minha apresentação oral deste artigo em Kingston, Jean Delisle destacou que parecia haver muitos paralelos entre a tradução feminista contemporânea e o trabalho de tradutores medievais. Tradutores da Idade Média também eram forçados a lidar com neologismos e adaptar termos desconhecidos em línguas-alvo flutuantes e instáveis; além disso, desempenharam um importante papel na definição e estabelecimento de novas normas de linguagem. Se estendermos essa analogia e mantivermos certa dose de otimismo, podemos imaginar as tradutoras feministas de hoje tendo um impacto no desenvolvimento da linguagem sem gênero, ou pelo menos consciente do gênero, daqui a vários séculos!

${ }^{52} \mathrm{~N}$. das T.: Termo que remete à transformação e performance. 


\section{Referências}

Benjamin, Walter. "Die Aufgabe des Ubersetzers". Illuminationen, Frankfurt am Main: Suhrkamp, 1977.

Bersianik, Louky. L’Euguélionne. Montreal : La Presse, 1976.

Boucher, Denise. Les Fées ont soif. Montreal : Éditions Intermède, 1978.

Boucher, Denise. The Fairies are thirsty. Tradução de Alan Brown. Vancouver: Talonbooks, 1982.

Brossard, Nicole. “L’Écrivain”. La Nef des sorcières, Montreal : Quinze, 1976.

Brossard, Nicole. "The Writer". Tradução de Linda Gaboriau. Fireweed, (197980): 5-6.

Brossard, Nicole. L'Amèr ou le chapitre effrité. Montreal : Quinze, 1977. Montreal: L'Hexagone, 1988.

Brossard, Nicole. These Our Mothers or: The Disintegrating Chapter. Tradução de Barbara Godard. Toronto: Coach House Press, 1983.

Brossard, Nicole. (Ed.). Les Stratégies du réel. Montreal : La barre du jour, 1979.

Brossard, Nicole. The Story so Far. Vários tradutores. Toronto: Coach House Press, 1979.

Chamberlain, Lori. "Gender and the Metaphorics of Translation". Signs: Journal of Women and Culture in Society 13.3, (1988): 454-472.

Derrida, Jacques. La Dissémination. Paris : Seuil, 1972. 
Derrida, Jacques. "Des Tours de Babel". Difference in Translation. Joseph P. Graham (Ed.), Cornell University Press, 1985.

Derrida, Jacques. “Survive”. Parages, Paris : Galilée, 1986.

Godard, Barbara. "Preface to These Our Mothers". These Our Mothers or: The Disintegrating Chapter, Brossard, Nicole, Toronto: Coach House Press, 1983.

Godard, Barbara. "Translating and Sexual Difference". Resources for Feminist Research 13.3, (1984): 13-16.

Godard, Barbara. "Theorizing Feminist Discourse/Translation". Mapping Literature, The Art and Politics of Translation, David Homel and Sherry Simon (Eds.), Montreal: Vehicule Press, 1988.

Homel, David. "Lise Gauvin astutely explains Quebec to Outsiders". The Gazette April 21, 1990.

Johnson, Barbara. "Preface to Dissemination". Dissemination, Jacques Derrida, Chicago: University of Chicago Press, 1981.

Lewis, Philip. "The Measure of Translation Effects". Difference in Translation, Joseph P. Graham (Ed.), Cornell University Press: 1985.

De Lotbinière-Harwood, Susanne. "Preface to Letters from Another". Letters from Another, Brossard, Nicole, Toronto : Women's Press, 1990.

Sabourin, Claude. "Les Numéros 'femmes' de La BJ/NBJ". Voix et images X.2, (1985) : 125-132.

Scott, Howard. Louky Bersianik's L'Euguélionne: Problems of Translating the Critique of Language in New Quebec Feminist Writing, Master's Thesis, Concordia University, Montreal, 1984. 
Wildeman, Marlene. "Preface to The Aerial Letter". The Aerial Letter, Nicole Brossard, Toronto: Women's Press, 1988.

Recebido em: $26 / 11 / 2020$

Aceito em: 05/02/2021 Publicado em maio de 2021

Luise von Flotow. E-mail: flotow@uOttawa.ca. ORCID: https://orcid.org/00000002-5729-1369.

Ofir Bergemann De Aguiar. E-mail: ofir@ufg.br. ORCID: https://orcid. org/0000-0002-5822-8484.

Lilian Virginia Porto. E-mail: lilianporto@ufg.br. ORCID: https://orcid. org/0000-0002-5822-8484. 